\title{
ERRATUM
}

\section{Erratum to: Topical Isopropyl Unoprostone for Retinitis Pigmentosa: Microperimetric Results of the Phase 2 Clinical Study}

\author{
Shuichi Yamamoto • Takeshi Sugawara - Akira Murakami • Mitsuru Nakazawa • \\ Nobuhisa Nao-i $\cdot$ Shigeki Machida $\cdot$ Yuko Wada $\cdot$ Yukihiko Mashima $\cdot$ Yozo Miyake
}

To view enhanced content go to www.ophthalmology-open.com

Published online: January 23, 2013

(C) The Author(s) 2013. This article is published with open access at Springerlink.com

Erratum to: Ophthalmol Ther (2012) 1:5

DOI 10.1007/s40123-012-0005-9

The authors of the above-mentioned paper would like to make the following adjustment to their article.

In the author list, the surname of the last author is spelt incorrectly. The name should read 'Yozo Miyake,' and not 'Yozo Myake.'

The online version of the original article can be found under doi:10.1007/s40123-012-0005-9.

S. Yamamoto $(\bowtie) \cdot$ T. Sugawara

Department of Ophthalmology and Visual Science, Chiba University Graduate School of Medicine, Chiba, Japan

e-mail: shuyama@faculty.chiba-u.jp

\section{A. Murakami}

Department of Ophthalmology, Faculty of

Medicine, Juntendo University, Tokyo, Japan

M. Nakazawa

Department of Ophthalmology, Hirosaki University

Graduate School of Medicine, Hirosaki, Japan

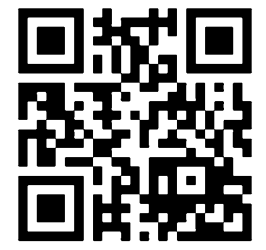

Enhanced content for this article is

available on the journal web site:

www.ophthalmology-open.com
The authors thank Springer Healthcare for publishing the correction.

\section{OPEN ACCESS}

This article is distributed under the terms of the Creative Commons Attribution Noncommercial License which permits any noncommercial use, distribution, and reproduction in any medium, provided the original author(s) and the source are credited.

\section{N. Nao-i}

Department of Ophthalmology,

Faculty of Medicine, University of Miyazaki,

Miyazaki, Japan

\section{S. Machida}

Department of Ophthalmology,

Iwate Medical University, Morioka, Japan

Y. Wada

Yuko Wada Eye Clinic, Sendai, Japan

Y. Mashima

R-tech Ueno Ltd., Tokyo, Japan

Y. Mashima

Department of Ophthalmology,

Keio University School of Medicine,

Tokyo, Japan

Y. Miyake

Aichi Medical University, Nagakute, Japan 